\title{
Trifecta has lower gradient and less prosthesis-patient mismatch than Mosaic Ultra in the aortic position: A prospective randomized study
}

\author{
Bjørn Braathen, MD, PhD, ${ }^{a}$ Trygve Husebye, MD, PhD, ${ }^{b}$ Ida G. Lunde, MSc, $\mathrm{PhD},{ }^{c, d}$ and
} Theis Tønnessen, MD, $\mathrm{PhD}^{\mathrm{a}, \mathrm{d}}$

\begin{abstract}
Objective: When aortic valve replacement is needed, a biological valve is usually implanted in patients older than age 60 to 65 years. A large valvular opening area is important to avoid prosthesis-patient mismatch and facilitate reverse left ventricular remodeling. The Trifecta biological valve (St Jude Medical, St Paul, Minn) is, because of its design, believed to reduce transvalvular gradient compared with other biological valves, especially in smaller annuli. Several retrospective studies have compared transvalvular gradients of implanted valves prostheses using the respective manufacturers given size and not the actual annulus size measured by a metric sizer. This makes comparison of the hemodynamic properties of different valve brands and sizes difficult. We therefore performed a prospective randomized study, using the same metric sizer to measure annulus size, and compared hemodynamic profiles of the Trifecta to our standard Mosaic Ultra biological valve (Medtronic, Minneapolis, Minn).
\end{abstract}

Methods: Ninety elective patients with small to medium annulus diameter undergoing aortic valve replacement were randomized to either Trifecta or Mosaic Ultra. After native valve removal and decalcification, a Hegar-sizer was used to measure true annulus size. Then the largest possible valve of either brand was implanted according to the randomization protocol. Echocardiography was performed 6 months postoperatively.

Results: Baseline parameters of the 2 cohorts were comparable. There were lower transvalvular gradients in the Trifecta compared with the Mosaic Ultra group for the given annulus sizes. Severe prosthesis-patient mismatch was present in $28 \%$ of patients in the Mosaic group and 3\% of patients in the Trifecta group.

Conclusions: Trifecta showed lower transvalvular gradients and less severe prosthesis-patient mismatch compared with Mosaic Ultra for the given annulus sizes. ClinicalTrials.gov Protocol ID: 2011/2596/REK. (J Thorac Cardiovasc Surg 2019;158:1032-9)

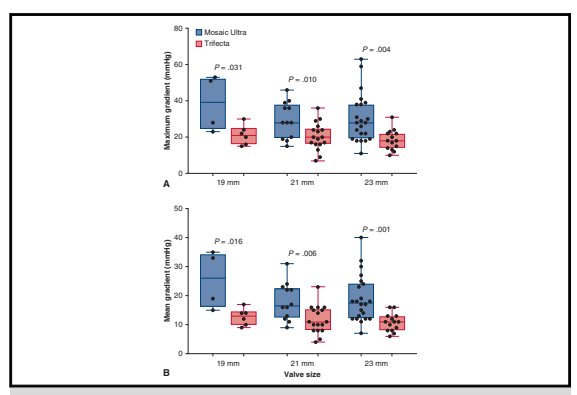

Significantly lower gradients were seen in Trifecta (St Jude Medical, St Paul, Minn) compared with Mosaic Ultra (Medtronic, Minneapolis, Minn) valves.

\section{Central Message}

Biological aortic valve replacement with the Trifecta valve prosthesis (St Jude Medical, St Paul, Minn) showed significantly lower transvalvular gradients compared with Mosaic Ultra valve prosthesis (Medtronic, Minneapolis, Minn) for the given annulus sizes.

\section{Perspective}

This prospective randomized study revealed lower transvalvular gradients and lower number of prosthesis-patient mismatch in patients undergoing aortic valve replacement with the Trifecta (St Jude Medical, St Paul, Minn) compared with the Mosaic Ultra (Medtronic, Minneapolis, Minn) biological prosthesis. This might advocate the choice of the Trifecta over the Mosaic Ultra in patients where lower gradients and better hemodynamic performance are warranted.

See Commentary page 1040 .

\footnotetext{
From the ${ }^{\mathrm{a}}$ Departments of Cardiothoracic Surgery and ${ }^{\mathrm{b}}$ Cardiology, Oslo University Hospital, Ullevål, Norway; ${ }^{\mathrm{c} I n s t i t u t e}$ for Experimental Medical Research and Center for Heart Failure Research, Oslo, Norway; and dUniversity of Oslo, Oslo, Norway.

Received for publication Feb 27, 2018; revisions received Oct 24, 2018; accepted for publication Nov 5, 2018; available ahead of print Jan 8, 2019.

Address for reprints: Theis Tønnessen, MD, PhD, Department of Cardiothoracic Surgery, Oslo University Hospital, Kirkevn 166, 0407 Oslo, Norway (E-mail: theis. tonnessen@medisin.uio.no).

0022-5223/\$36.00

Copyright (c) 2018 by The American Association for Thoracic Surgery

https://doi.org/10.1016/j.jtcvs.2018.11.020
}

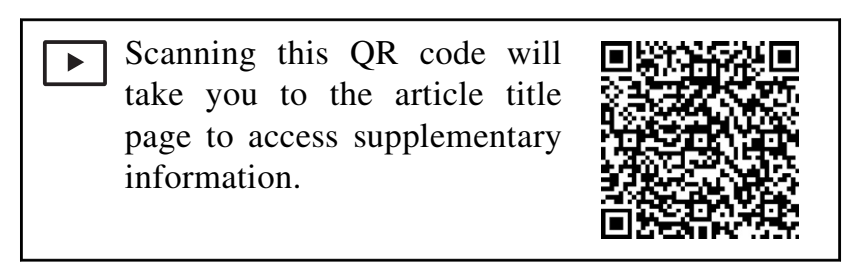



Abbreviations and Acronyms
AVR $=$ aortic valve replacement
$\mathrm{BSA}=$ body surface area
$\mathrm{EOAI}=$ effective orifice area index
SVD $=$ structural valve degeneration

The incidence of aortic valve stenosis is increasing due to the increase in average life expectancy. Aortic valve replacement (AVR) is the only effective treatment for severe aortic stenosis. Usually, patients older than age 60 to 65 years receive a biological valve prosthesis when AVR is needed. Long-time durability of the prosthesis and the hemodynamic performance are important factors when choosing valve prosthesis for each individual patient. Transvalvular gradient and effective valve orifice area are related to both left ventricular remodeling, prosthesispatient mismatch, and patient prognosis. ${ }^{1-3}$ Most studies comparing different biological valve prostheses have used the manufacturer's given valve size. However, the size of a valve prosthesis is not necessarily comparable between brands because companies might report anything from the size of the outer diameter to the inner diameter. This becomes obvious when sizers and valves from different companies are directly compared. Therefore, using the manufacturer's given size when comparing different brands of valves might give biased results.

The Trifecta pericardial valve (St Jude Medical, St Paul, Minn) has a design that is claimed by the manufacturer to give superior hemodynamic performance, which also has been reported in clinical studies. ${ }^{4,5}$ Although a few studies exist comparing Trifecta to other biological valves, most are retrospective in design and comparison has been based on the manufacturer's given valve size and not on the true annulus size measured by a metric sizer. ${ }^{6,7}$ In a prospective randomized study we tested the hypothesis that the Trifecta valve has lower transvalvular gradients and less prosthesis-patient mismatch compared with our standard Mosaic Ultra valve (Medtronic, Minneapolis, Minn) in small and medium sized annuli. To avoid the above-mentioned bias by comparing valve sizes given by the manufacturing companies, we first measured true annular diameter by a metric Hegar sizer after native valve removal. Then we implanted the largest possible valve of either brand according to the randomization protocol. Thus, we were able to measure the transvalvular gradient of the largest prosthesis that would fit the patient, regardless of the size given by the manufacturer.

\section{METHODS}

This study was investigator initiated, designed, and driven by the authors independently of the valve manufacturing companies. The study protocol was approved by the local ethical committee and conducted in accordance with the principles of the Declaration of Helsinki and all patients provided informed consent.

\section{Study Population and Design}

The present study was designed as a prospective randomized study. Eligible for inclusion were patients who by preoperative echocardiography had an annulus diameter $\leq 23 \mathrm{~mm}$, left ventricular ejection fraction $\geq 50 \%$ and 1 of the following: significant aortic stenosis defined as mean aortic valve gradient $>40 \mathrm{~mm} \mathrm{Hg}$ or aortic valve area $<0.7 \mathrm{~cm}^{2}$, significant aortic regurgitation defined as grade 3 out of 3 and left ventricular end-diastolic diameter $>70 \mathrm{~mm}$ and/or left ventricular systolic diameter $>50 \mathrm{~mm}$, and patients who required treatment for aortic stenosis or regurgitation in combination with other significant concomitant heart disease. Between September 2012 and November 2014, 90 consecutive patients undergoing elective surgical AVR at Oslo University Hospital Ullevål, Oslo, Norway, were included and randomized. The randomization was performed by opening of opaque and sealed envelopes after induction of anesthesia, but before crossclamping the aorta for practical reasons. Every cohort of 10 patients was blockrandomized containing the same number of Trifecta and Mosaic Ultra valves in random order to ensure an even distribution of the 2 biological valves with time. Except for the principal investigator, none of the participating surgeons were aware of the block-randomization or how many patients were included to minimize potential bias (Video 1). After native valve removal and decalcification, the annulus diameter was measured by a metric Hegar sizer. Then the largest possible valve of either brand was implanted according to the randomization protocol. Patients in whom a valve larger than $23 \mathrm{~mm}$ was implanted were excluded from the study.

Twelve patients were excluded from the study because of too large annulus diameter, too large implanted valve, or lack of measurement by Hegar sizer. Three patients were later excluded because they were lost to follow-up for the following reasons: 1 patient died of cerebral stroke and 1 patient died of lung infection and renal failure. A third patient underwent reoperation for endocarditis.

\section{Transthoracic Echocardiography at 6 Months}

Transthoracic echocardiography was performed 6 months postoperatively in all patients by the same cardiologist who was blinded to treatment group. Measurements of the transvalvular maximum and mean gradients and calculations of the effective orifice area index (EOAI) were done in accordance with international guidelines. ${ }^{8}$ The simplified Bernoulli equation was used to calculate peak and mean pressure gradients across the

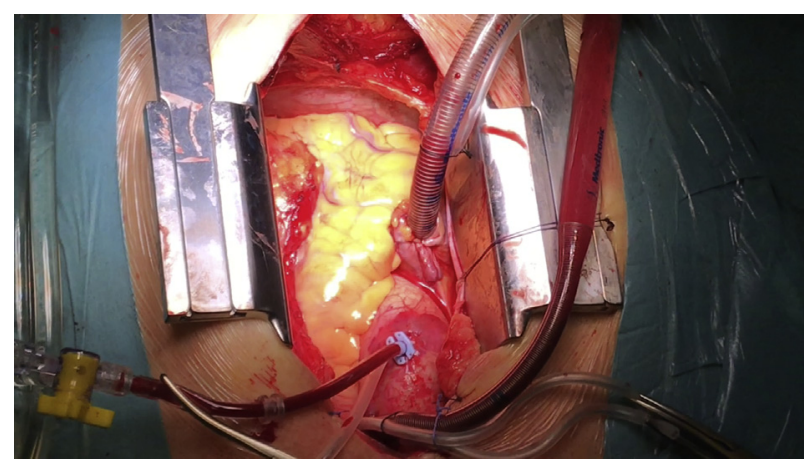

VIDEO 1. Surgical procedure and annulus measurement. Video available at: https://www.jtcvs.org/article/S0022-5223(18)32967-2/fulltext. 
TABLE 1. Preoperative characteristics of patients randomized to receive a Trifecta (St Jude Medical, St Paul, Minn) or Mosaic Ultra (Medtronic, Minneapolis, Minn) biological aortic valve replacement

\begin{tabular}{lcc}
\hline & Trifecta & Mosaic Ultra \\
\hline Number of patients & 37 & 38 \\
\hline Age $(\mathrm{y})$ & $77(71-81)$ & $77(72-81)$ \\
Female patients & 11 & 19 \\
$\begin{array}{l}\text { Combined procedures } \\
\text { Intraventricular septum diameter } \\
\text { in end-diastole }(\mathrm{cm})\end{array}$ & $1.3(1.1-1.6)$ & $1.3(1.1-1.4)$ \\
$\begin{array}{l}\text { Creatinine }(\mu \mathrm{mol} / \mathrm{L}) \\
\text { New York Heart Association } \\
\quad \text { functional class }\end{array}$ & $36(71-99)$ & $91(75-103)$ \\
Atrial fibrillation & $3(3)$ & $3(3)$ \\
\hline
\end{tabular}

Values are presented as $n, n(\%)$, or median ( $25 \%-75 \%$ percentile).

prosthetic valve. Three consecutive cardiac cycles were recorded, 5 if atrial fibrillation was present. Peak gradient, mean pressure gradient, and EOAI were calculated as the mean over these cycles. Body surface area (BSA) at 6 months was calculated by the Du Bois method.

\section{Anesthesia and Operative Technique}

Before intubation, the patients were given benzodiazepine (diazepam or flunitrazepam), fentanyl (3-5 $\mu \mathrm{g} / \mathrm{kg})$, thiopental $(0.5-2.0 \mathrm{mg} / \mathrm{kg})$, and cisatracurium $(0.15 \mathrm{mg} / \mathrm{kg})$ or pancuronium bromide $(0.1-0.15 \mathrm{mg} / \mathrm{kg})$. The anesthesia was maintained with sevoflurane ( $1 \%-2 \%$ inspired), propofol $(2-3 \mathrm{mg} / \mathrm{kg} / \mathrm{h})$ or midazolam $(0.02-0.04 \mathrm{mg} / \mathrm{kg})$, and fentanyl $(1-2 \mu \mathrm{g} / \mathrm{kg})$ during extracorporeal circulation. Anticoagulation was performed with systemic heparinization to maintain an activated clotting time beyond 480 seconds. All operations were performed using extracorporeal circulation with a roller pump, ascending aortic cannulation, single venous cannulation, and moderate systemic hypothermia $\left(32^{\circ} \mathrm{C}-34^{\circ} \mathrm{C}\right)$. All valves were implanted in a supraannular position with pledgeted U-sutures and the pledget placed on the ventricular side. No root enlargements were performed. Myocardial protection and cardiac arrest was, as described previously, ${ }^{9,10}$ induced by blood cardioplegia delivered at a temperature of $4^{\circ} \mathrm{C}$ to $8^{\circ} \mathrm{C}$ and repeated every 20 minutes. The ratio of cardioplegia solution to blood was 1:4 with the following content: $179.1 \mathrm{mmol} / \mathrm{L}$ sodium, $22.2 \mathrm{mmol} / \mathrm{L}$ potassium, $18.6 \mathrm{mmol} / \mathrm{L}$ magnesium, $2.8 \mathrm{mmol} / \mathrm{L}$ calcium, $1.1 \mathrm{mmol} / \mathrm{L}$ procaine hydrocloride, $6.5 \mathrm{mmol} / \mathrm{L}$ acetate, $77.6 \mathrm{mmol} / \mathrm{L}$ chloride, $32.8 \mathrm{mmol} / \mathrm{L}$ hydrogen carbonate, and $\mathrm{pH} 7.30$ to 7.40 .

\section{Use of Inotropic Support}

No rigid protocol was established regarding inotropic support and it was administered after clinical judgments individually by the surgeon or

TABLE 2. Intra- and postoperative patient characteristics

\begin{tabular}{|c|c|c|c|}
\hline & Trifecta* & Mosaic Ultra $\left.\right|^{\dagger}$ & $P$ value \\
\hline Number of patients & 37 & 38 & \\
\hline AF postoperative & 8 & 19 & .01 \\
\hline AF 6 mo postoperative & 7 & 3 & .2 \\
\hline Onset AF 6 mo postoperative & 1 & 2 & .5 \\
\hline $\operatorname{EOAI}\left(\mathrm{cm}^{2} / \mathrm{m}^{2}\right)$ & $0.94(0.77-1.08)$ & $0.76(0.63-0.82)$ & $<.001$ \\
\hline NYHA functional class 6 mo postoperative & $1(1-1)$ & $1(1-2)$ & .3 \\
\hline Valve $\geq$ Hegar sizer & 9 & 17 & .06 \\
\hline IVSD reduction 6 mo postoperative & 24 & 23 & .4 \\
\hline CK-MB max $(\mu \mathrm{g} / \mathrm{L})$ & $30(19-44)$ & $21(17-38)$ & .8 \\
\hline Troponin-T max (ng/L) & $564(328-822)$ & $515(341-1027)$ & .8 \\
\hline Postoperative creatinine ( $\mu \mathrm{mol} / \mathrm{L})$ & $75(64-91)$ & $80(65-107)$ & 6 \\
\hline Postoperative inotropic infusion & 3 & 1 & .4 \\
\hline 30-d mortality & 0 & 0 & \\
\hline Myocardial infarction & 1 & 2 & 1 \\
\hline Extracorporeal circulation (min) & $103(91-125)$ & $104(88-128)$ & .9 \\
\hline Crossclamp (min) & $80(67-94)$ & $79(64-99)$ & .8 \\
\hline Postarrest recovery (min) & $21(16-30)$ & $20(15-29)$ & .7 \\
\hline BSA 6 mo postoperative $\left(\mathrm{m}^{2}\right)$ & $1.88(1.74-2.01)$ & $1.94(1.82-2.14)$ & .05 \\
\hline Postoperative inotropic infusion & 3 & 1 & .4 \\
\hline Number of patients & 33 & 36 & \\
\hline EOAI $<0.65$ & 1 & 10 & .007 \\
\hline $\mathrm{EOAI} \leq 0.85$ & 12 & 31 & $<.001$ \\
\hline
\end{tabular}

Values are presented as n or median (25\%-75\% percentile). AF, Atrial fibrillation; EOAI, effective orifice area index; NYHA, New York Heart Association; IVSD, intraventricular septum diameter in end-diastole; $C K-M B$, creatine kinase-muscle/brain; $B S A$, body surface area (Du Bois method). *Trifecta biological aortic valve (St Jude Medical, St Paul, Minn). † Mosaic Ultra biological aortic valve (Medtronic, Minneapolis, Minn). 
anesthesiologist mainly to keep mean arterial pressure above $60 \mathrm{~mm} \mathrm{Hg}$. The use of inotropic infusions longer than 20 minutes during the first 24 postoperative hours was registered.

\section{Registration of Atrial Fibrillation}

All patients were monitored continuously with telemetry the first 3 postoperative days. A 12-lead echocardiogram was recorded every day and patients with episodes of atrial fibrillation postoperatively, without a history of atrial fibrillation preoperatively, were recorded.

\section{Measurements of Cardiac Marker Proteins}

Venous blood samples were collected before the operation and 7, 20, 44, and 68 hours postoperatively. Serum troponin-T concentration was measured by using electrochemi-luminescence immunoassay on the Roche immunoassay analyzer (Roche Holdings, Basel, Switzerland). Serum creatine kinase-muscle/brain concentration was measured by using electrochemi-luminescence immunoassay on the Roche Elecsys 2010 immunoassay analyser (Roche Holdings).

\section{Criteria for Perioperative Myocardial Infarction}

Two of the 3 following criteria had to be fulfilled to diagnose a myocardial infarction: appearance of a new postoperative Q-wave in echocardiogram of more than 0.03 seconds, creatine kinase-muscle/brain $\geq 100 \mathrm{and} /$ or troponin- $\mathrm{T} \geq 3.0 \mu \mathrm{g} / \mathrm{L}$, and a new hypokinetic or akinetic myocardial area by echocardiography.

\section{Study End Points}

The study end points were mean and maximum gradients and EOAI measured 6 months postoperatively with transthoracic echocardiography.

\section{Statistical Analysis}

The sample size was calculated a priori based on the results from previous studies. ${ }^{11-15}$ A cohort of 13 patients per valve size and type with an expected difference in mean gradient of $7.9 \mathrm{~mm} \mathrm{Hg}$ and a standard deviation of $5.4 \mathrm{~mm} \mathrm{Hg}$, as obtained from previous studies, would give a power of 0.95 with a 2 -sided $5 \%$ significance level. Because of uncertainty regarding loss to follow-up, we included a total of 90 (and not the calculated 78) patients in the study. Data are presented as single data points, medians, $25 \%$ to $75 \%$ percentiles, and minimum and maximum values. Normal distribution was tested using the Shapiro-Wilk normality test. Differences between the 2 groups were analyzed by Student $t$ test or MannWhitney rank-sum test according to whether data met the criteria for normal or nonnormal distribution, respectively. Comparisons of groups with dichotomous data were analysed by the Fisher exact test for sample sizes $<5$ and the $\chi^{2}$ test for 5 or more observations. Pearson regression



A



FIGURE 1. A and B, Maximum and mean transvalvular gradients, respectively, in Trifecta (St Jude Medical, St Paul, Minn) and Mosaic Ultra (Medtronic, Minneapolis, Minn) valves 6 months postoperatively according to annulus size as measured by Hegar sizer. The data are shown as single values (circles), and box and whiskers plots where the upper and lower borders of the box represent the $25 \%$ and $75 \%$ percentiles, the middle horizontal line represents the median, and the upper and lower whiskers represent the maximum and minimum values. Statistically significant differences between the 2 groups for the given sizes are shown with respective $P$ values. Number of patients in each group: Trifecta: $21 \mathrm{~mm}, \mathrm{n}=5 ; 22 \mathrm{~mm}, \mathrm{n}=6 ; 23 \mathrm{~mm}, \mathrm{n}=12 ; 24 \mathrm{~mm}$, $\mathrm{n}=6$; and $25 \mathrm{~mm}, \mathrm{n}=4$. Mosaic Ultra: $21 \mathrm{~mm}, \mathrm{n}=9 ; 22 \mathrm{~mm}, \mathrm{n}=4 ; 23 \mathrm{~mm}, \mathrm{n}=9 ; 24 \mathrm{~mm} \mathrm{n}=7$; and $25 \mathrm{~mm}, \mathrm{n}=6$. 
analysis was used for correlations. $P<.05$ was considered as statistically significant. Because of suboptimal echocardiographic visibility, effective orifice area could not be estimated in a few patients, and those missing values were omitted from statistical calculations. Statistical analyses were performed in SigmaStat, version 3.1 (Jandel Scientific GmbH, Erkrath, Germany) or Prism 7 (GraphPad Software, La Jolla, Calif).

\section{RESULTS}

\section{Patient Characteristics}

The baseline characteristics of patients are shown in Table 1, whereas their pre- and postoperative characteristics are shown in Table 2. Most variables were comparable between the 2 groups with no 30-days mortality. There was a tendency to more women and higher BSA in the Mosaic Ultra group. Markers of myocardial damage did not differ, and crossclamp time and extracorporeal circulation time were comparable. Immediately postoperatively, there was significantly more atrial fibrillation in the Mosaic Ultra group (Table 2).

\section{Transvalvular Gradients}

Both the maximum and mean transvalvular gradients were almost $50 \%$ lower in the Trifecta group compared with the Mosaic Ultra group for the given annulus sizes as measured by the metric Hegar sizer (Figure 1, $A$ and $B$ ). Only 5 patients underwent operation with a measured annulus of $19 \mathrm{~mm}$ (3 patients) or $20 \mathrm{~mm}$ ( 2 patients) and therefore not compared statistically or included in Figure 1. When comparing valves of the same size as given by the manufacturer, there were also significantly lower gradients in the Trifecta group (Figure 2). Valve size was


FIGURE 2. A and B, Maximum and mean transvalvular gradients, respectively, in Trifecta (St Jude Medical, St Paul, Minn) and Mosaic Ultra (Medtronic, Minneapolis, Minn) prosthetic valves 6 months postoperatively according to prosthetic valve size. The data are shown as single values (circles), and box and whiskers plots where the upper and lower borders of the box represent the $25 \%$ and $75 \%$ percentiles, the middle horizontal line represents the median, and the upper and lower whiskers represent the maximum and minimum values. Statistically significant differences between the 2 groups for the given sizes are shown with respective $P$ values. Number of patients in each group: Trifecta: $19 \mathrm{~mm}, \mathrm{n}=6 ; 21 \mathrm{~mm}, \mathrm{n}=17$; and $23 \mathrm{~mm}, \mathrm{n}=14 ;$ Mosaic Ultra: $19 \mathrm{~mm}, \mathrm{n}=4$; $21 \mathrm{~mm}, \mathrm{n}=12$; and $23 \mathrm{~mm}, \mathrm{n}=22$. 




A

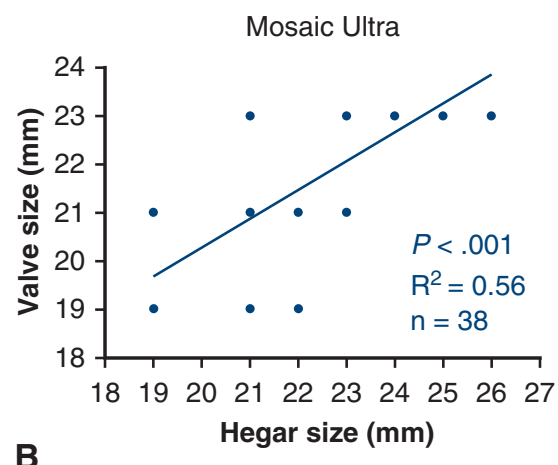

B



C

FIGURE 3. Pearson regression analyses of Hegar size versus implanted valve size (ie, size measured by the respective manufacturer's sizer). A, Trifecta $(\mathrm{n}=37)$ (St Jude Medical, St Paul, Minn). B, Mosaic Ultra $(\mathrm{n}=38)$ (Medtronic, Minneapolis, Minn). Some of the dots represent more than 1 observation. C, For smaller annuli there was a tendency to put in a larger prostheses in the Mosaic Ultra group as measured by the manufacturer's sizer.

borderline significantly larger than the measured annulus diameter by Hegar sizer in 17 of the patients $(45 \%)$ in the Mosaic group and in 9 of the patients $(24 \%)$ in the Trifecta group, indicating that the outer diameter of the Mosaic valve is smaller than the Trifecta for any size given by the respective company. This is also reflected in Figure 3 where true annulus size measured by the Hegar sizer is plotted against the size of the implanted valve of the 2 valve types.

\section{Prosthesis-Patient Mismatch}

EAOI was significantly higher in the Trifecta compared with the Mosaic Ultra (Figure 4 and Table 2). In line with this, severe prosthesis-patient mismatch (EOAI $\left.<0.65 \mathrm{~cm}^{2} / \mathrm{m}^{2}\right)$ was found in 10 out of 36 patients $(28 \%)$ in the Mosaic group and 1 out of 33 patients in the Trifecta group $(3 \%)$. Moderate prosthesis-patient mismatch (EOAI $\leq 0.85 \mathrm{~cm}^{2} / \mathrm{m}^{2}$ ) was found in 33 of 36 patients in the Mosaic group $(92 \%)$ and in 12 out of 33 patients in the Trifecta group $(36 \%)$.

\section{DISCUSSION}

The main finding of our prospective randomized study comparing the Trifecta to the Mosaic Ultra biological valve in the aortic position shows that the Trifecta valve had almost half the transvalvular gradient compared with the Mosaic Ultra valve for measured annulus sizes up to $25 \mathrm{~mm}$. Moreover, severe prosthesis-patient mismatch was almost absent in the Trifecta group compared with 10 out of 36 patients $(28 \%)$ in the Mosaic Ultra group.

Most published studies comparing biological valves are retrospective in design. ${ }^{16-18}$ Furthermore, when comparing valve sizes, the manufacturer's valve-specific sizers have often been used without taking the true annulus diameter into account. For example, it is well known that


FIGURE 4. A, Effective orifice area index (EOAI) in Trifecta (St Jude Medical, St Paul, Minn) and Mosaic Ultra (Medtronic, Minneapolis, Minn) valve groups 6 months postoperatively. The data are shown as box and whiskers plots where the upper and lower borders of the box represent the $25 \%$ and $75 \%$ percentiles, the middle horizontal line represents the median, and the upper and lower whiskers represent the maximum and minimum values. B and C, Number of patients with severe and moderate prosthesis-patient mismatch in Trifecta and Mosaic Ultra valves 6 months postoperatively for EOAI $<0.65 \mathrm{~cm}^{2} / \mathrm{m}^{2}$ and EAOI $\leq 0.85 \mathrm{~cm}^{2} / \mathrm{m}^{2}$, respectively. Statistically significant differences between the 2 groups are shown with respective $P$ values. 
$19 \mathrm{~mm}$ valves from 2 different manufacturers might potentially have significant differences both in valve diameter and effective orifice area. Therefore, it is questionable whether valves prostheses from different companies with the same reported size are comparable. To circumvent this potential source of bias we measured true annulus size after native valve removal and decalcification with a metric Hegar sizer. Subsequently, we implanted the largest of either valve brand according to the randomization protocol. Because we implanted 17 Mosaic valves and only 9 Trifecta valves with reported size larger than the measured annulus size by Hegar, this indicates that the diameter of the Mosaic valve tend to be smaller than the Trifecta valve for any given size reported by the manufacturers.

Favorable hemodynamic characteristics using the Trifecta valve have previously been reported. ${ }^{19}$ However, few prospective randomized studies comparing this valve to others have been published. The mean transvalvular gradient of the Trifecta valve in the present study is comparable to that reported by others. ${ }^{20,21}$ Only 1 out of 33 patients had severe prosthesis-patient mismatch compared with 10 out of 36 in the Mosaic group. ${ }^{22}$ The clinical relevance of this finding is not studied here, and both prosthetic valves have good function over time, ${ }^{20-23}$ but it might indicate better survival for patients without severe prosthesis-patient mismatch. ${ }^{1-3,24-26}$ No significant difference in septum thickness 6 months after implant was observed between groups. However, in younger and physically active patients, the favorable hemodynamic profile of the Trifecta compared with the Mosaic Ultra valve theoretically might be of benefit. On the other hand, Mosaic Ultra might be easier to handle in small aortic roots (a cinch implant system facilitating valve insertion and tying behind the stent posts), has longer follow-up data with good results, ${ }^{27-}$ ${ }_{29}$ and carries a lower cost. Although data on intermediate follow-up of the Trifecta valve has been published, longterm data is still awaited. One large study by Lehman and colleagues $^{21}$ with data from 918 patients with a median follow-up of 2.7 years for the Trifecta valve reports a 5 -year freedom from structural valve degeneration (SVD) of $97.9 \% .{ }^{21}$ Another study by Goldman and colleagues ${ }^{20}$ reports a 6-years freedom from reoperation due to structural valve degeneration of $97.3 \%$. However, it should be noted that there are a few anecdotal reports of early SVD of the Trifecta valve. ${ }^{30,31}$ On the other hand, Ansemli and colleagues ${ }^{28}$ published a study on the Mosaic porcine bioprosthesis where the median follow-up was 8.5 years and they reported freedom from SVD at 5, 10, and 15 years of $99.3 \%, 97.9 \%$, and $86.3 \%$, respectively. Comparable to this study, Jamison and colleagues ${ }^{29}$ followed patients with implanted Mosaic valves up to 12 years and found freedom from reoperation caused by SVD of $91 \%$.

We found significantly lower incidence of atrial fibrillation in the Trifecta group postoperatively. The present study was not designed to examine atrial fibrillation in the 2 valve groups. However, it might be speculated that increased left ventricular or atrial pressures in patients with Mosaic Ultra valves with higher transvalvular gradient contribute to this finding.

\section{Limitations}

The present study has some limitations. There is a relatively low number of patients in each of the 2 valve groups and for each valve size. However, the statistical power calculation performed a priori combined with the prospective randomized design of the study make us believe that the pronounced difference in gradients for the given valve sizes is valid. Moreover, we have only examined hemodynamic performance. Durability of the 2 valves was beyond the scope of this study. A further limitation is that although the echocardiographer was blinded to which valve the patient had received when he did follow-up examination at 6 months, it is possible to distinguish between the 2 valves when echocardiographic measurements are performed. At baseline, there were borderline-significant differences in gender and BSA and we cannot completely exclude that this could have influenced our measurements.

\section{CONCLUSIONS}

In this prospective randomized study using an objective measurement of the true aortic annulus size, we found lower transvalvular gradients in the Trifecta compared with the Mosaic Ultra biological valve for any given aortic annulus size examined. This was also reflected in a significantly lower number of prosthesis-patient mismatches in the Trifecta group. Our findings might advocate use of Trifecta instead of the Mosaic Ultra valve in patients where lower gradients and better hemodynamic performance is warranted.

\section{Conflict of Interest Statement}

The Medtronic company, manufacturer of the Mosaic Ultra valve, provided Drs Braathen and Tønnessen with travel expenses to international cardiothoracic meetings and St Jude Medical, manufacturer of the Trifecta valve, provided an unrestricted grant of 50000 NOK. All other authors have nothing to disclose with regard to commercial support.

The authors thank the staff of the Department of Cardiothoracic Surgery and the Department of Cardiothoracic Anesthesiology, Oslo University Hospital, Ulleval, for helping to perform the study. The authors also thank operation-coordinator Vibeke Balas Andersen for valuable work regarding collecting data.

\section{References}

1. Rao V, Jamieson E, Ivanov J, Armstrong S, David TE. Prosthesis-patient mismatch affects survival after aortic valve replacement. Circulation. 2000; 102(19 Suppl 3):III5-9. 
2. Mannacio V, Mannacio L, Mango E, Antignano A, Mottola M, Caparrotti S, et al. Severe prosthesis-patient mismatch after aortic valve replacement for aortic stenosis: analysis of risk factors for early and long-term mortality. J Cardiol. 2017; 69:333-9.

3. Head SJ, Mokhles MM, Osnabrugge RL, Pibarot P, Mack MJ, Takkenberg JJ, et al. The impact of prosthesis-patient mismatch on long-term survival after aortic valve replacement: a systematic review and meta-analysis of 34 observational studies comprising 27186 patients with 133141 patient-years. Eur Heart J. 2012;33:1518-29.

4. Deutsch MA, Prinzing A, Fiegl K, Wottke M, Badiu CC, Krane M, et al. Early hemodynamic performance of a latest generation supra-annular aortic bioprosthesis: experience from a large single-centre series. Eur J Cardio-Thorac Surg. 2016;49:1691-8.

5. Fouquet O, Flecher E, Nzomvuama A, Remadi JP, Biere L, Donal E, et al. Hemodynamic performance of small supra-annular Trifecta bioprosthesis: results from a French multicenter study. Interactive Cardiovasc Thorac Surg. 2016;22: 439-44.

6. Bach DS, Patel HJ, Kolias TJ, Deeb GM. Randomized comparison of exercise haemodynamics of Freestyle, Magna Ease and Trifecta bioprostheses after aortic valve replacement for severe aortic stenosis. Eur J Cardiothorac Surg. 2016;50: 361-7.

7. Wendt D, Thielmann M, Plicht B, Assmann J, Price V, Neuhäuser M, et al. The new St Jude Trifecta versus Carpentier-Edwards Perimount Magna and Magna Ease aortic bioprothesis: is there a hemodynamic superiority? J Thorac Cardiovasc Surg. 2014; 147:1553-60

8. Baumgartner H, Hung J, Bermejo J, Chambers JB, Evangelista A, Griffin BP, et al. Echocardiographic assessment of valve stenosis: EAE/ASE recommendations for clinical practice. Eur J Echocardiogr. 2009;10:1-25.

9. Braathen B, Jeppsson A, Scherstén H, Hagen OM, Vengen Ø, Rexius H, et al. One single dose of histidine-tryptophan-ketoglutarate solution gives equally good myocardial protection in elective mitral valve surgery as repetitive cold blood cardioplegia: a prospective randomized study. J Thorac Cardiovasc Surg. 2011;141:995-1001.

10. Braathen B, Tønnessen T. Cold blood cardioplegia reduces the increase in cardiac enzyme levels compared with cold crystalloid cardioplegia in patients undergoing aortic valve replacement for isolated aortic stenosis. J Thorac Cardiovasc Surg. 2010; 139:874-80

11. Eichinger WB, Botzenhardt F, Guenzinger R, Bleiziffer S, Keithahn A, Bauernschmitt R, et al. The effective orifice area/patient aortic annulus area ratio: a better way to compare different bioprostheses? A prospective randomized comparison of the Mosaic and Perimount bioprostheses in the aortic position. J Heart Valve Dis. 2004;13:382-8.

12. Eichinger WB, Botzenhardt F, Günzinger R, Kemkes BM, Bleese N, Sosnowski A, et al. Left ventricular mass regression after aortic valve replacement with the mosaic bioprosthesis. J Heart Valve Dis. 2002;11:529-36.

13. Bavaria JE, Desai ND, Cheung A, Petracek MR, Groh MA, Borger MA, et al. The St Jude medical Trifecta aortic pericardial valve: results from a global, multicenter, prospective clinical study. J Thorac Cardiovasc Surg. 2014;147:590-7.

14. Jamieson WR, Janusz MT, MacNab J, Henderson C. Hemodynamic comparison of second- and third-generation stented bioprostheses in aortic valve replacement. Ann Thorac Surg. 2001;71(5 Suppl):S282-4.

15. Eichinger W, Botzenhardt F, Gunzinger R, Kemkes BM, Sosnowski A, Maiza D, et al. European experience with the Mosaic bioprosthesis. J Thorac Cardiovasc Surg. 2002; 124:333-9.
16. Fiegl K, Deutsch MA, Rondak IC, Lange R, Guenzinge R. Matched comparison of two different biological prostheses for complete supra-annular aortic valve replacement. Thorac Cardiovasc Surg. 2015;63:459-66.

17. Ghoneim A, Bouhout I, Demers P, Mazine A, Francispillai M, El-Hamamsy I, et al. Management of small aortic annulus in the era of sutureless valves: a comparative study among different biological options. J Thorac Cardiovasc Surg. 2016;152:1019-28.

18. Ruzicka DJ, Hettich I, Hutter A, Bleiziffer S, Badiu CC, Bauernschmitt R, et al. The complete supraannular concept: in vivo hemodynamics of bovine and porcine aortic bioprostheses. Circulation. 2009;120(11 Suppl):S139-45.

19. Tasca G, Martino AS, Giannico F, Riva B, Redaelli P, Lobiati E, et al. Hemodynamic comparison between Trifecta and Freestyle valves implanted in smal aortic roots. One-year echocardiographic results from a prospective randomized study. J Heart Valve Dis. 2015;24:360-7.

20. Goldman S, Cheung A, Bavaria JE, Petracek MR, Groh MA, Schaff HV Midterm, multicenter clinical and hemodynamic results for the Trifecta aortic pericardial valve. J Thorac Cardiovasc Surg. 2017;153:561-9.

21. Lehmann S, Meyer A, Schroeter T, Uhlemann M, Fischer J, Leontyev S, et al Midterm durability and hemodynamic performance of a third-generation bovine pericardial prosthetic aortic valve: the Leipzig experience. Ann Thorac Surg. 2017;103:1933-40.

22. Walther T, Lehmann S, Falk V, Metz S, Doll N, Rastan A, et al. Prospectively randomized evaluation of stented xenograft hemodynamic function in the aortic position. Circulation. 2004;110:II74-8.

23. Matsumoto Y, Tomoyuki F, Hiroki H, Shimahara Y, Sato S, Kobayashi J. Hemodynamic performance and durability of Mosaic bioprostheses for aortic valve replacement, up to 13 years. Circulation. 2015;79:1044-51.

24. Hernandez-Vaquero D, Diaz R, Pascual I, Rozado J, De la Hera JM, Leon V, et al. The prevalence of patient-prosthesis mismatch can be reduced using the Trifecta aortic prosthesis. Ann Thorac Surg. 2018;105:144-52.

25. Swinkels BM, de Mol BA, Kelder JC, Vermeulen FE, Berg M. Prosthesis-patien mismatch after aortic valve replacement: effect on long-term survival. Ann Thorac Surg. 2016;101:1388-94.

26. Kulik A, Burwash I, Kapila V, Mesana T, Ruel M. Long-term outcomes after valve replacements for low-gradient aortic stenosis. Impact of prosthesispatient mismatch. Circulation. 2006;114:1553-8.

27. Riess FC, Bader R, Cramer E, Hansen L, Kleijnen B, Wahl G, et al. Hemodynamic performance of the Medtronic Mosaic porcine bioprosthesis up to ten years. Ann Thorac Surg. 2007;83:1310-8.

28. Anselmi A, Flecher E, Ruggieri VG, Harmouche M, Langanay T, Corbineau H, et al. Long-term results of the Medtronic Mosaic porcine bioprosthesis in the aortic position. J Thorac Cardiovasc Surg. 2014;147:1884-91.

29. Jamieson E, Riess FC, Raudkivi PJ, Metras J, Busse EF, Goldstein J, et al. Medtronic Mosaic porcine bioprosthesis: assessment of 12-year performance. $J$ Thorac Cardiovasc Surg. 2011;142:302-7.

30. Kalra A, Rehman H, Ramchandani M, Barker CM, Lawrie GM, Reul RM, et al Early Trifecta valve failure: report of a cluster of cases from a tertiary care referral center. J Thorac Cardiovasc Surg. 2017;154:1235-40.

31. Hamamoto M, Kobayashi T, Ozawa M, Yoshimura K. Pure cusp tear of Trifecta bioprosthesis 2 years after aortic valve replacement. Ann Thorac Cardiovasc Surg. 2017;23:157-60.

Key Words: aortic valve, transvalvular gradient, prosthesis-patient mismatch 